\title{
Thinking emergence as interaffecting: approaching and contextualizing Eugene Gendlin's Process Model
}

\author{
Donata Schoeller ${ }^{1} \cdot$ Neil Dunaetz ${ }^{2}$
}

Published online: 23 February 2018

(C) The Author(s) 2018. This article is an open access publication

\begin{abstract}
Prior to A Process Model, Gendlin's theoretical and practical work focused on the interfacing of bodily-felt meaningfulness and symbolization. In $A$ Process Model, Gendlin does something much wider and more philosophically primary. The hermeneutic and pragmatist distinction between the concept of experience, on the one hand, and actual experiential process, on the other, becomes for Gendlin the methodological basis for a radical reconceptualization of the body. Wittgenstein's formulation of "meaning" as "language-use in situations" is spelled out by Gendlin in embodied terms, yielding a profound new grasp of language, meaning, situation, language-use and culture as interactional body-process. Gendlin, in building his text, answers the pragmatist critique of a wrong progression of thinking where the results of an inquiry are read back to be its premises. With his central concept "eveving" ("everything interaffected by everything") Gendlin shows how the seeming determinacy of preceding structure is opened in the actual occurring. He thereby elaborates a new conception of continuity where the possibility for responsive novelty is emergent in the event itself. The conceptual development of the text itself instances this kind of emergent novelty. We will somewhat follow Gendlin's own path in using language-in-situations as entry-point into his more fundamental process-thinking, thereby asking ourselves how to engage his new kind of model. In the last part, we introduce some of the philosophical roots of Gendlin's A Process Model.
\end{abstract}

Donata Schoeller

schoeller@uni-koblenz.de

Neil Dunaetz

neilr@sonic.net

1 University of Koblenz, Koblenz, Germany

2 Gardnerville, NV, USA 
Keywords Organism · Environment - Interaction · Situation · Language-use · Meaning · Experiencing · Process · Expression · Function · Implicit · Body · Emergence $\cdot$ Felt-sense $\cdot$ Practice

\section{Introduction}

In martial arts instead of directly countering the force of the opponent one learns, in Kung Fu for instance, to employ that energy as one's own move. This makes it difficult to say which is my move or the other's move. The happening move is each time both, each being a result of one responsive organization, one whole process. Eugene Gendlin's philosophical project opens up an analogous dynamic of ordinary experience. Gendlin's "move" teaches us that experience cannot be understood as only an object of theories. He demonstrates instead how to systematically think not only about, but in and with experience. The radically reflective style of Gendlin's thinking shows how next moves and precise symbolic distinctions emerge, affecting the process they emerge from. Gendlin understands this process as instancing an order he calls "responsive." Understanding its implicit precision needs one's engaging it.

Wilhelm Dilthey expanded the philosophical vocabulary by distinguishing experiencing (Erleben), from the concept of "experience" (Erfahrung). In Gendlin's work, this distinction becomes the basis for a radical reflective way of thinking that is able to include the experiencing body. This is of primary importance in approaching Gendlin's A Process Model (Gendlin 2017a). ${ }^{1}$ (More extensive discussion of the philosophical roots of the model is to be found at the end of this paper.)

Contemporary philosophy is rediscovering the importance of philosophical practice by describing its ancient forms and discussing possibilities for such practice today. For many years now, Gendlin's practices, called "Focusing" and "Thinking-At-the-Edge," empower people to open the experienced intricacy of questions and intuitions that matter deeply and to profoundly formulate what is at stake. They teach people how to reflect on something not explicit, but experientially implicit in the question or in the issue (Claxton 2006; DeLoch 2010; Gendlin 1981, 2004, 2007; Mahrer 2006; Tokumaru 2011; Schoeller 2016; Walkerden 2005, 2009). Directly referring to what Gendlin calls the felt sense allows one to speak from a background that functions in our arguments and logical progressions, thereby adding a new level of transparency to systematic thinking.

Today Matthew Ratcliffe's descriptions of "feelings of being" (Ratcliffe 2008) come close to what Gendlin means by "felt sense." Yet Gendlin's practices allow one to reflectively move in accordance with a precision that can be felt only by engaging how the situation-as-experienced involves much more than positions, arguments or judgements. Practices involving reflective interaction with what is

\footnotetext{
1 Eugene Gendlin's A Process Model will appear at Northwestern University Press in November 2017. We (D.S. and N.D.) have worked from Gendlin's manuscript that has been available online until May 2017. We therefore cite chapters and sections rather than pages when referring to this book.
} 
experientially implicit have the quality of dance moves: how one moves in relation to, is formed by, and is a change in, what one moves with. In these interactivelyresponsive processes there is something surprising to be discovered: with Stanley Cavell one might describe this as "finding one's own voice."

The philosophical lifework of Gendlin opens up a new ground that enables thinking for oneself to occur today. This cannot easily be classified along the lines of the usual philosophical categories. What Gendlin offers is not a new metaphysics, epistemology or ontology. Nor is it phenomenology, philosophy of language, philosophy of psychology, or philosophy of science. He does contribute greatly to these various discourses, as well as to the problems faced by environmental studies, feminist theory, ethics, consciousness studies, theories of evolution, and still others.

A Process Model is not meant as another philosophical system. Rather, as a model it enables one not to be trapped in systems, but to move between what John Dewey calls the "universe of experience" and the "universe of discourse." (Dewey 1938: 69) This freedom in thinking reminds us of Kant when he says that the goal of modern philosophy is to empower people to dare to think for themselves: sapere aude! If in the past, as Kant notes, it was tradition and authority that inhibited thinking for oneself, today it is mass and social media and the exponential growth of expert knowledge in every domain. To think for oneself in today's world has by no means become easier than in Kant's day!

The challenges taken up in Gendlin's model arise in traditions that still make it extremely difficult to think (in) interaction. Cutting-edge cognitive scientists today note with a tone of astonishment that consciousness is not to be conceived as an internal phenomenon inside the brain, but as arising from body-environment interaction. ${ }^{2}$ A Process Model anticipates both this needed turn in thinking, and also the standards of inquiry into consciousness that are emphasized by avant-garde thinkers of embodiment who say that it is "the body-and-world-involving conception of ourselves that the best new science as well as philosophy should lead us to endorse." (Noë 2009: 7) Beginning with the premise of "interaction first" as his consistent methodological basis, Gendlin provides fresh ways to enter into what is routinely described as the "hard problem of consciousness" (Chalmers 1996) and the "really hard problem" of meaning (Flanagan 2009).

The kind of deep re-conceptualization enacted in A Process Model involves difficulties that ground-breaking philosophers of the past were all too aware of. Kant, for instance, notes that when philosophers use familiar terms in radically new ways, everything at first must seem nonsensical, given that the reader cannot yet follow the thoughts of the author, but only his own thoughts- which have by habit become the natural way of thinking (Kant 1998). This is indeed what makes reading A Process Model difficult. It would be easier if this book were a critique, a description or a deconstruction of habits that have become the "natural" way of

\footnotetext{
${ }^{2}$ Alva Noë for instance introduces his book Out of our Head in the following way: "In this book I advance the truly astonishing hypothesis: to understand consciousness in humans and animals, we must look not inward, into the recesses of our insides; rather, we need to look to the ways in which each of us, as a whole animal, carries on the processes of living in and with and in response to the world around us. The subject of experience is not a bit of your body. You are not your brain. The brain, rather, is part of what you are." (Noë 2009: 7).
} 
thinking. It would also be easier if this were a programmatic text about certain definite suggested changes in philosophical approaches. However, this book is called a model, because as a model it makes the change it is "about." In other words, it models concepts able to work in interaction as a methodological basis for every further step of thinking.

Kant was all too aware of the challenges involved in the reception of a radically transformative philosophical text. He recognized the danger of projecting habitual ways of thinking onto the new ways in which certain traditional terms are being used. We find a similar sensitivity in Hegel, who spoke of the risk of introductions forecasting something that in practice can only be learned after a thorough workingthrough. In the foreword to the Phenomenology of the Spirit, he criticizes as impatience the desire to make the content and purpose of a book recognizable at the very beginning (Hegel 1970: 33). He grimly notes that such impatience wants the impossible: striving to reach the goal without the means. For this same reason, Gendlin himself has been skeptical about an introduction to his A Process Modelhe did not write one.

Prior to A Process Model, Gendlin's theoretical and practical work focused on the interfacing of bodily-felt meaningfulness and symbolization (Gendlin 1962). In writing A Process Model, Gendlin does something much wider and more philosophical primary. We will follow Gendlin's own path in using language-insituations as entry-point into his process-thinking, thereby asking ourselves how to engage his new kind of model.

\section{Language-in-situations as entry}

We understand our complex situations and contexts without having to first put them into words. It is often the case that descriptions, concepts and definitions seem too imprecise to grasp the way in which events and things matter to us. Against the backdrop of experience, the use of descriptive and theoretical language may seem stereotypical, sterile and "off the mark." In daily life, one knows exactly what to say in situations. We rarely have to think about it. And we rarely think about why we don't have to think about it. At times, what we say may clarify and advance the situation, while at other times our saying may leave the situation still needing what it needed. But how do we know? And how can we think this remarkable and tacit "attunement," as Stanley Cavell calls it (Cavell 1979: 32)?

Scientific and philosophical research have not yet allowed us to better understand this phenomenal situatedness. The difficulties involved in precisely conceiving embodied experience in its relation to language grows from a tradition in which the very formulation of the problem is already problematic: Often, what are touted as "precise concepts" of experience reduce the phenomenon explained or make it disappear altogether. And the other way around: In reference to ordinary experience, how can one speak of "precision" in the first place? Is this not a contradictio in adjecto? Does not conceptual precision begin beyond ordinary, so-called "subjective" experience, that is to say, only at the level of theories, propositions, logical rules, and definitions that lie beyond experience itself? 
The difficulty in these questions involves the cut between body and mind in Western thinking, and with it, the deep-going assumption of "objectivity" pertaining to the public sphere of observable "bodies" and of "subjectivity" pertaining to the "insides" of minds. In either case, meaning seems to consist either in representing what is there, inside or outside, or, alternatively, in constructing reality through language. Philosophers, old and new, discuss and argue along the lines of these representative and constructive models. In this impasse, Wittgenstein points to the obvious: namely, there is no specific meaning without a situation. This has brought a major shift in philosophical debates on language. Ordinary language philosophy takes off from here by inquiring into the criteria of the meanings of words and speech acts, and their truths, according to situations. But this kind of investigation cannot say why words sometimes come easy in certain situations and at other times not, and why it is possible to situationally make sense at all, and sometimes to make very novel sense.

Some philosophers today turn to literature, finding something there that has little to do with representation or construction of things. Language used in literature brings along with it rich experiential effects that open up an intricate universe of experience. At the end of reading a text, or listening to someone, one may reawaken as if from a spell, as Merleau-Ponty beautifully describes (Merleau-Ponty 1945). In A Process Model, this power of language-in literature and elsewherebecomes eminently thinkable, as the text unfolds each situation and each word as a "gigantic system of implicit sequences and contexts" (Gendlin. 2017a: VII-B, Appendix to f.). The reader will thus find here concepts modeling the non-reducible thickness of what happens when words work in situations.

The Wittgensteinian lesson of contexts co-determining meaning is thereby spelled out by Gendlin in interactionally embodied terms. Wittgenstein's formula of "meaning as language use in situations," cited so frequently by philosophers of language, leaves opaque just what is "a situation," as well as what is the doing inherent in "use." Gendlin thinks about situation and use in a way that helps us understand why a slight shift in sensing a situation can at times make for more change than "one could ever describe with thousands of words." (Gendlin 1997a: VIII-Ae). ${ }^{3}$ Words did not fall from "heaven like separate hail stones" (Gendlin 1997a: VII-Be), but rather developed as an integrated elaboration of what is already thick behavioral bodily living in complex contexts. Working through A Process Model one comes to grasp how human bodies are situational and situations are embodied, and therefore, "how we can feel complex situations, how the body can come up with an answer to a complex human living question we cannot figure out, how body and cognition are not just split apart." (Gendlin 1997a: VII-Be).

\footnotetext{
3 Note that in editing Gendlin's manuscript in preparation for publication by Northwestern University Press, Gendlin's original chapter designation of "VIII-A" was changed to only "VIII." We will use Gendlin's original "VIII-A" designation for this chapter because doing so preserves a significant understanding regarding the respective developmental stage. Specifically (starting with chapter VI), the "A" designation of the chapters involves the early development of a new kind of continuity while the " $\mathrm{B}$ " designation involves the development of a whole context of that respective kind. Much of Gendlin's meaning is wound up in these chapter titles; they are much more than a mere method of enumeration.
} 
It is as embodied and felt that a situation is highly specific even before it is articulated in words. Of all of Gendlin's theoretical works, A Process Model, in particular, thinks sharply into the functional conditions of this experiential intricacy, giving a surprisingly fine conceptual entry into the kind of complex order that is at work when, for example, we feel we have not quite yet said what we mean, and also its role in forming what we can then say next. Gendlin shows how feeling and meaning are not just internal-not autistic-but rather environmental: strings of changes in living interaction. Correspondingly, "situations" are not the mere "external" conditions or facts which a spectator might note, but specific lived complexities involving wider past and future.

By deriving complex capacities, such as perception, consciousness, and symbolization, as unbroken continuity of body-environment interaction, Gendlin obviates the familiar constructs of internal/external and "subjective/objective," arriving at an understanding of embodied universals that do not drop out the many rich details of their respective particular instances. Gendlin's different understanding of situations, language and experienced meaning becomes possible on the basis of his careful explication of "implying." Building on Whitehead's groundbreaking concept of "concrescence" (Whitehead 1979), Gendlin explicates what he means by implying with a new verb: "eveving" ("everything interaffected by everything") (Gendlin 1997a: IV-Ae) wherein each bit of happening process becomes thinkable as a unique fresh-forming involving the wide sweep of embodied past. Working with Mead's important insight of a past in the present, ${ }^{4}$ Gendlin thinks with novel precision how past experience "functions" in the fresh-forming event, not as it was in its earlier happening, (i.e., "not as itself"), but as "already-affected by" everything. The specific role of past experience in shaping what happens is thus creatively determined only in and by the immediate occurring itself. Gendlin opens this up systematically in his model so that it becomes the starting point for an alternative ground of thinking on a basic level. He is doing something new with language, making emergence function in the basic concepts he uses. In Gendlin's conception, occurring "occurs into" and changes implying (eveving). Therefore we can think how it is that any event is always much more change than just what an observer would see: most change is implicit!

As Ralph Waldo Emerson noticed, the most personal experience is also in some way universal. Gendlin's derivation of language and situational meaningfulness on the basis of occurring into eveving, shows how Emerson's observation can and indeed must be the case.

\section{Engaging a new kind of model}

It was only after many discussions with him that we (D.S. and N.D.) were able to grasp why Gendlin can offer his reader only a few scarcely defined notions at the beginning. With every new step, with every next definition and turn, the conditions that facilitate the further thought process become more explicit. In transitions not

\footnotetext{
$\overline{4}$ We say more on Mead's influence in the final section of this paper.
} 
logically predictable, the text builds its fundaments, its capacity for going on. Only once it is created and used does each further conceptual formation prove itself to be a sustainable and expandable methodological move. The continuity of such a progression is not a succession from one established premise to the next, from one proposition to the following, according to a few explicit laws, rules or arguments. In one of our conversations with him, Gendlin explained that "I build the model always fresh and new. I build and build and then I also show: there is no way further here, we first need to devise new means of explication." 5

Therefore the reader has to deal with a bare preliminary understanding of the notions offered at the beginning of A Process Model. This is especially true for the model's key term "implying." Gendlin openly admits the impossibility of giving a satisfying definition at the start. The meaning of the word "implying" needs to form through the specific manner in which it works. What is thus practiced makes for the uniqueness of the model: the evolving meaning of "implying" allows one to consider the responsive order involved in the very development of (its) meaning.

Terrence Deacon powerfully describes an intrinsic incompleteness, an "integral withoutness" as a characteristic of human driving forces (Deacon 2012: 3). Values, ideas, goals and concepts are not, after all, concrete entities. Deacon calls them "absential features," in the sense of not being materially present or energetically measurable. He points strongly to the failure of science to grasp the real effect(s) of "absential features," creating a gap wherein what is most meaningful to human life becomes unreal in the world of science. "No wonder," Deacon writes, that "the allpervasive success of the sciences in the last century has been paralleled by a rebirth of fundamentalist faith and a deep distrust of the secular determination of human values." (Deacon 2012:12). To be unable to conceive a function, which from a material point of view is based on something non-existent, not only hinders our ability to understand ourselves, but also, as Deacon formulates, "it has effectively left a vast fraction of the world orphaned from theories that are presumed to apply to everything." (Deacon 2012: 12).

Gendlin makes us hugely more competent in systematically thinking the functions of an implying that is not materially occurring, but that is always part of what does concretely occur. So closely integrated are "implying" and "occurring" in Gendlin's work that to think one is already to think the other.

To think further and further into the role of "implying" in life process, as Gendlin's text asks of us, requires one to think "from here," from an experientiallyembodied place, instead of "from nowhere." Anchoring this "from here" place methodologically into the main concepts, A Process Model ensures that meaningful experience does not become "the very hard problem," as it does in scientific approaches to cognition. ${ }^{6}$

In school one learns early to consider, measure and understand observable "things," to draw diagrams in order to grasp "relations," to distance oneself in order to get an "objective" perspective on phenomena. To understand Gendlin's major concepts (such as "interaction-first," "implying," "occurring into implying,"

\footnotetext{
5 Conversation of September 9th, 2014, Spring Valley, NY.

${ }^{6}$ See Noë (2009), and footnote 2 .
} 
"carrying forward"), one needs to de-learn these distancing tactics. Instead, one must learn to deliberately notice, for example, what it is like to be hungry and then to eat, what it is like to walk, what it is like to breathe, what it is like to find a word for something (or not to find one) — and what it is like to read the very words you are now reading.

Engaging this bodily experiencing in the reading process, one finds in one's own embodied happening what the text is saying. To think "from here" need not assume a fixed, already-there something that can be considered from a separate place. Rather, reflection involves, indeed is, the fresh-forming happening of what is reflected upon.

This text's shifting between two ways of thinking, one marked as "old" and the other as "new," should be understood as a change of perspective: as an exercise in shifting from one set of assumptions and methodologies to a very different one in order to realize the deep-cutting consequences of thinking from and in embodied interaction, or not.

A similar shifting between ways of thinking can be found in Wittgenstein's writings. In his Philosophical Investigations he demonstrates a number of questions that lead philosophical thinking into traps, like a fly that does not find its way out of the fly-bottle (Wittgenstein 2001: $§ 308$ ). By spelling out the hidden assumptions in such questions, Wittgenstein shows the fundamental difference it makes if, on the one hand, the investigation is regulated by assumptions of internal procedures and entities warranting the meaning of words, or if, on the other hand, one is actually ready "to look" at the way meaning is made by the actual use of language in situations. The very assumptions implicit in the questions have the power to hinder the actual "looking." (They work as these assumptions because they are not looked at.) The difference made when one does actually look for the meaning qua use in situations - a highly reflective turn-is enormous.

Gendlin asks for a similar fundamental difference of approach. The widespread habit of not attending to the embodied living process involved in having meaning, is itself based on the assumption that experience starts with perception and that meaning refers only to observable entities, objects, and states of affairs. This makes for an intellectual context in which the givenness of perceivable entities as the basis of experience and knowledge is assumed or critiqued. Either way, the underlying subject-object dichotomy drops out the embodied interactional process from the kinds of explanations given to things, bodies, minds, states of affairs, and including interactional process itself. A set of observations, categories, concepts or logical rules becomes the determining factor for everything, i.e., is taken as the grounds for an "objective" grasp of the world.

Thinking this way, aspects of world are cut off that do not fit into the concept, reducing phenomena in ways that obstruct one's access to anything beyond the description. Along these lines, Theodor Adorno formulates a fundamental critique of the use of concepts, hoping to overcome this limitation by sketching out what he calls the utopia of a different way of thinking. Such thinking would not determine and identify the phenomena it conceives, but would instead open it up. The most important feature of a philosophy of the future would be its ability to behold the full, unreduced experience in the medium of conceptual reflection. Such a philosophy, 
Adorno writes, would become infinite in what he calls a "subtle" (or "tender") way. It would see cognition never owning its objects entirely (Adorno 1975).

What for Adorno is utopia, Gendlin enacts. His model is exactly this opening up which the development of its concepts facilitate. These are not concepts in the usual sense of being identical with what they are "about." What they could be about was not something there beforehand (to be "represented"), but something that emerges freshly in the embodied process of thinking, speaking or reading-emerges with precision even if it is also richly unfinished.

\section{Why would it matter?}

What difference can such a philosophy make in dealing with real problems? Let's consider a big one. Today the impact of human activity on the planet and its manifold life is almost too great to fully comprehend: The wholesale disfiguring of landscapes by agriculture, industry, war and urbanization; the widespread degradation and destruction of oceanic and terrestrial habitats; the increasingly rapid advance of anthropogenic climate change; the resulting ongoing mass extinction; and all that these changes imply. These problems of "environment" are thought about in quite different ways depending on who is doing the thinking. If we were to artificially and superficially say that they fall into two camps, those who observe and measure from the outside with the developed powers of science, and those who think and act in terms of their own experienced meaningfulness and "mattering,"7 we see that neither group is able to articulate the problem in a way that motivates the broader population to change entrenched institutions and practices. The underlying assumptions of science preemptively divorce its thinking from experienced meaningfulness, while those who would think and act from experienced meaningfulness are hampered by an inability to conceptually explain how experienced meaningfulness could itself be a sound basis for policy decisions and actions. In the view of science, felt meaningfulness does not stand the test of objectivity. But those who do not question the practical validity of felt meaningfulness also cannot explain it in the terms that we use for explaining what concretely occurs. People in the first group may not wish to admit that their work, too, is motivated and guided by the very experience of meaningfulness which their explicit theories would judge as "not objective," while people in the second group often reach for the "objective" explanations of the former group in an attempt to socially justify positions and actions based on their own experienced meaningfulness. No one seems able to connect enough dots to explain what caring, valuing, meaning, mattering or feeling love for, actually are, much less how there might be something like actionable precision and accuracy involved in their experiential occurring.

Here could come the same question-why does it matter? - but now we must see that this question comes after and out of the above impasse. When something

\footnotetext{
${ }^{7}$ Our use of this word here and hereafter is inspired by Karen Barad's Meeting the Universe Halfway (Barad 2007).
} 
matters to someone, why does it? How is it that something could matter such that when it does it is immediately the basis for directed action? Is it facts that matter? Is it culturally-scripted self-interests that matter? Is it the impact of information and facts which makes something matter, and if so, what shall we mean by "impact"? What makes for the differences between people who risk their lives to stop human insanities and people who are content to fiddle while Rome burns? How is it that so many disengage from what (to others) matters so much? What is mattering (caring for, valuing, loving) such that it can be so universal in its occurrence yet so seemingly opaque to incisive thinking? Why have we not been able to think about something so important, indeed about importance itself? Does "mattering" play the game of being "hard to think" or has thinking not yet found the necessary traction to penetrate occurrences of mattering?

This impasse is born of fundamental assumptions inhering in much current thinking, and especially in explanatory thinking. "Objectivity" defines a reality where the observer-as-living must by definition be absent. Such a conception precludes the possibility of intrinsic relationality and meaningfulness. Then, meaning and relationality become dependent on the observer's formulations and definitions. Space too, is objectified and held to exist independently of things and events that happen "in" it, an empty container for "real" things. Similarly, the construct of time as a simple linearity artificializes all occurring and denies the temporal complexity of experienced continuity outright. The "objectively real" time and space is one we don't inhabit because as defined it cannot afford, much less bear, our thickness of experience! Such "objectivity" divides an explainable "real" world off from our experience of living-in-a-world; and thus we come to seem unreal. But now we must ask, how would we be able to think differently, especially when we need to explain something carefully? This would surely require a fundamentally different kind of thinking but how can we achieve that?

Gendlin radically reconceives "the body" (i.e., living process) in such a way that the same basic schematic terms work to explicate all living capacities, from the most primitive to the most sophisticated activities of consciousness, language, and meaning. His strong move is to think living process as not only occurring but as also always implying. He begins at a primitive level so that the evolutionary emergence of new more complex process can be thinkable as a sure continuity without conceptual gaps. He wants thinking, as he says, "to make us possible":

We will further develop concepts, in terms of which culture, language and thinking can speak from themselves, not only as has been the case up to now, but with terms that will let us enter into our intricacy (Gendlin 2017a: end of V-B).

Gendlin's consistent reliance on and explication of the body's implicit functioning provides a startling new entry into aspects of experience that before now have seemed opaque and resistant to clear thinking. Each further step of conceptual development is enacted with the implicit (both in Gendlin's writing and in the reader's reading). In this way Gendlin's concepts instance what they mean as one freshly enters into what one thinks. We cannot overstate the productive power of this. Because the model works at such a basic level of thinking and experiencing it is 
intrinsically a new capacity to think into anything, including so much that Gendlin does not mention (e.g., how animal process is inherently experienced meaningfulness). When anything is considered in the living terms of this model it becomes more and newly differentiated, understood and meaningful. Meaning is creatively amplified by working where meaning happens: in the relation between explicit occurring and implicit bodily relevance.

We are deeply misled when we are told that this planet and its life are something "out there" and that our feeling about all that is only something "subjective" in a closed-off "inside." This book not only breaks the spell of this and other dominant older constructions, it also teaches us how to surf an advancing edge of fresh new thinking, so that our thinking and living no longer has to be subsumed within fixed conceptual categories: Neither the old confining ones we have inherited, nor the "better" ones we make today, nor even the "better" better ones we hopefully will make tomorrow.

\section{Some historical roots}

Gendlin's text begins abruptly with strange terminology, preceded only by a short recommendation to read it as if the concepts "came out of nowhere." But in a volume dedicated to his philosophy of language Gendlin writes: "The tradition is implicit in any thought and discussion, not only when it is overtly the topic." (Gendlin 1997b: 297) The concepts that should be taken as if they came from "nowhere" are implicitly loaded with the history of ideas, with direct and indirect allusions and references to thinkers on whose shoulders Gendlin stands.

In a single footnote, Gendlin names as sources the classical American pragmatists, as well as Wilhelm Dilthey, Alfred North Whitehead, Richard McKeon, Martin Heidegger, Maurice Merleau-Ponty, Ludwig Wittgenstein, Gottfried Leibniz, Plato and Aristotle. He indicates thereby the extensive history of philosophy that is actively at work in A Process Model. But why only a footnote for all this? The answer is not so simple.

Among classical pragmatists, phenomenologists, and hermeneuticians it is not unusual to introduce the newness of one's approach by going back to antiquity, contrasting the revolutionary potential of one's new thinking with traditions having very deep roots. For his part, Gendlin recognizes the cutting edge advances of these early thinkers. He sees Plato's dialogues as instancing a "responsive order." (Gendlin 2017b). In his translation of and commentary to Aristotle's De Anima, we see Gendlin's deep exploration and admiration of the Aristotelian methodology (Gendlin 2012). A Process Model ends by referring back to these two Greek pillars of Western thinking, invoking their work as emblematic of the capacity to think for oneself freshly.

This short article will leave much unsaid about Gendlin's productive relation to Husserl's Logical Investigations, to William James Radical Empiricism and Principles of Psychology, to Merleau-Ponty's Phenomenology of Perception, and also to Wittgenstein's Philosophical Investigations. Similarly, much fruitful research awaits in exploring Gendlin's relation to Leibniz's Monadology, to Kant's critique and to 
Hegel's dialectic, and also... the great inspiration he drew from Aristotle's De Animaand many others. Yet Gendlin cannot be considered a scholar of antiquity-or of pragmatism, phenomenology, or hermeneutics. Rather, his thinking goes on from, and in, the living environment of this earlier thinking. His relationship to Heidegger is but one good instance of this. Even though Gendlin refused to read Heidegger until very late (Gendlin 1986), he realized how much he had absorbed Heidegger's ideas through the work of Heidegger's students. Gendlin later translated "What is a Thing" (Gendlin 1967) and wrote an introduction that met with Heidegger's explicit appreciation (Gendlin 1989). He wrote an extended article on Heidegger's notion of "Dwelling" and also one on Heidegger's concept of "Befindlichkeit." (Gendlin 2017c). Years later, Gendlin adds a note to the online version of this latter article, saying: "Heidegger always urged people to go further from his new concepts. He would be glad that I am doing so. I don't change anything in his conception but I add the bodily-experiential dimension. Since he did not mean it in a bodily way at all, we should not attribute my concept of "Befindlichkeit" to Heidegger."

Gendlin's way of absorbing and going-on from previous thinkers is also seen in his relation to the classical pragmatists who, he once told us, were the "air he was breathing." Such directness in working with this tradition, Gendlin learned from his teacher Richard McKeon who was a student of Dewey. Gendlin writes: "McKeon inherited Pragmatism without claiming the label. Pragmatism always was a pluralism of many systems and approaches - a 'tool closet' full of various concepts and procedures." (Gendlin 1994). In A Process Model, Gendlin carries on with this "tool closet" very much in the spirit of his teacher: without "labeling." Gendlin's terms suggest an unhesitating familiarity with philosophers from which his thinking grows: "organism," "body-environment," "concretion," "function," "interaction," "implying," “event," "schema," "first," "second," "third," "gesture," "situation," "experiencing," "expression," "monad," etc. In using such terms, Gendlin makes his heritage recognizable, showing how deeply he imbibes his relevant predecessors, thinking further in the terms that inspire him.

A classical pragmatist such as John Dewey demonstrates how wrong is an order of succession in which the results of a reflective process are rendered as its premises. A phenomenologist like Husserl warns about a naiveté in which the process of scientific thinking becomes the very blind spot of scientific results. Therefore it seems no coincidence that Gendlin's model does not build on axiomatic concepts. Rather, the text's starting concepts require the further reflective process they themselves initiate in order to become the basis of a deeper understanding. We might call them "process-concepts" because they instance and explicate-instead of hide-the interaction needed to generate them. This intrinsically self-reflective methodology is Gendlin's response to the pragmatist and phenomenological critiques of scientific methodology. Reading A Process Model can be considered a systematic implementation of what Merleau-Ponty calls "radical reflection." Gendlin, however, stresses that reflection as a lived sequence newly re-generates what is reflected upon. ${ }^{8}$

\footnotetext{
${ }^{8}$ Feminist philosopher and physicist Karen Barad, today, arrives at a nicely parallel understanding in her critique of reflection as being "about mirroring and sameness," suggesting instead the alternative term "diffraction" as attending to "patterns of difference" (Barad 2007: 29).
} 
Gendlin demonstrates how subtle and deeply consequential an approach to cognition can be when it thinks in terms of "what works":

What is true is what works; but how does one decide what "works" means?

Dewey knew that the criteria arise within the feedback process itself, but he

(...) did not further explore the various kinds of feedback internal to a process

(Gendlin 1994: 386).

Gendlin shows with unprecedented conceptual precision how the occurring process itself is what determines whether something has "worked" or not. Staying true to the pragmatist understanding, he puts the occurring interaction first, before any conceptual scheme (including his own). On the basis of interaction-first, A Process Model makes major contributions to the philosophy of language by demonstrating how body, environment and meaning must be thought as together from the start, unseparable as one occurring process.

Gendlin embraces and carries on, albeit in very different ways, the pioneering project which Dewey undertakes in Logic: A Theory of Inquiry. Hoping for successors, Dewey lays out a grand plan of devising a natural understanding of logical structures. ${ }^{9}$ He develops a model of continuity from lower and less complex to higher and more complex (mental) activities, rigorously writing against the mainstream of his time, and against what is still the mainstream today in philosophy. Dewey understands ideas and cognitions not as entities inside a mind or brain, but on the basis of the interaction of environment and organism, as relationships that surpass the single organism.

Gendlin adopts Dewey's vocabulary in a cooperative spirit, in order to carry on the latter's project of continuity, yet with a different goal. In contrast to Dewey, Gendlin does not strive toward a changed epistemology and a changed understanding of logic (even though his model concerns both), but instead toward an understanding of living process as the continuity of body-environment right through sentience, meaning, language, culture and more. Doing this, Gendlin in effect reimplements Dewey's critique of a thinking habit that separates body and environment:

Unfortunately, however, a special philosophical interpretation may be unconsciously read into the common sense distinction. It will then be supposed that organism and environment are 'given' as independent things and interaction is a third independent thing which finally intervenes (Dewey 1938: 34)

Whereas Dewey insists that organisms exist only in active connections with their environment, and that organism and environment are "an integration," (Dewey 1938: 25). Gendlin formalizes this understanding on the first page of A Process Model with the concept "body-environment\#2" as a single indivisible term signifying "the process"; Gendlin thus makes Dewey’s critique operational.

\footnotetext{
9 "The present volume is an approach, not a closed treatise. The aim it hopes to fulfill is that of being a sufficiently coherent and systematic approach to move others to undertake the long cooperative work (never-ending in any case as long as inquiry continues) needed to test and fill in the framework which is outlined in this book." (Dewey 1938: 40).
} 
Gendlin also draws on Dewey's use of the term "implying." In his famous article "Qualitative Thinking" (Dewey 1984) as well as in his Logic-A Theory of Inquiry, Dewey introduces "implying," contrasting it with the logical term by emphasizing an open and yet regulative function manifesting the quality of a whole situation which can be felt, and through which relevant distinctions can be found. ${ }^{10}$ What Dewey points to presciently in these different places is methodologically and systematically worked through in Gendlin's philosophy. Gendlin thinks with and from an implying, unfolding the conditions of its open and yet precise functions. And he does this on the basis of the inseparability of organism-environment.

Gendlin's undertaking is also influenced by Charles Sanders Peirce, one of the founders of classical pragmatism, whose unconventional categories of "firstness," "secondness," and "thirdness" can be heard echoing in Gendlin's own derivation of our human capacity to think and live in terms of "kinds" and "categories." Peirce broke new ground with his categories of "firstness" and "secondness" in order to specify the conditions of meaning qua pre-conceptual embodied-environmental happening. He finds a new language breaking radically free from the philosophical canon and its well defined classical categories. Introducing "firstness," Peirce points to the iconic-relational function of a qualitative state or feeling before any distinctions, and with "secondness" he emphasizes the meaning-making role of an indexical happening here and now. Both are non-verbal aspects of how we relate to situations and events. Both feed into verbal meaning and interpretation, which constitute "thirdness." It is not coincidental that Gendlin chooses these terms to think into the multi-stage development of universals (words). Gendlin shows in compelling detail the implicit development of two earlier kinds of universality ("firsts" and "seconds") that must have preceded the kind of "kinds" or "categories" philosophers take to be the a priori condition of thinking. This conceptual progression in the text makes up Gendlin's step-by-step derivation of language as a bodily development. By thinking this in terms of the body's implicit functioning, Gendlin is able to show that kinds do not reduce to just commonalities, but rather keep and carry forward all the intricate situationally-specific details. The vast richness of living is "carried forward" in language use, but is never fully capturable in terms of verbal definition.

In taking behavioral interaction as the functional ground for the first happening of symbolic sequences, Gendlin continues to think with another classical pragmatist: George Herbert Mead. Like no one before him, Mead treats with great rigor the development of language based on interactional behavior and gestural coordination (e.g., in animal fighting). Mead directs the philosophy of language in a new direction by emphasizing the interactional, instead of the representational, basis of meaningful communication. But he also sharply analyzes the difference between gestures and symbols insofar as the latter are capable of accomplishing the same thing both when they are actively employed and when they are received. Mead stresses the importance of this difference between gesture and symbol, enabling philosophical thinking to take account of the exchange of meaning not just as an intersubjective happening but as a happening that lets the same thing happen in the

$\overline{10}$ See the excellent elaborations on these key notions by Jung (2009 $a, b)$. 
different participants of communication. How this can be possible on the interactional basis of meaning is the challenge taken up by Gendlin, who thinks the continuity (as well as the rupture) from the interactional gestures of animal behavior to the universal character of symbols. His model thus can be read as continuing and importantly elaborating the interactional symbolism Mead initiated.

Furthermore, Mead prefigures Gendlin's overall project when he spells out the challenge of thinking about emergence. Mead criticizes a way of thinking that attempts to grasp the newness of an event by introducing antecedent structures:

The difficulty that immediately presents itself is that the emergent has no sooner appeared than we set about rationalizing it, that is, we undertake to show that it, or at least the conditions that determine its appearance, can be found in the past that lay behind it. Thus the earlier past out of which it emerged as something which did not involve it are taken up into a more comprehensive past that does lead up to it. Now what this amounts to is that whatever does happen, even the emergent, happens under determining conditions - especially, from the standpoint of the exact sciences, under spatio-temporal conditions which lead to deducible conclusions as to what will happen within certain limits [...] (Mead 2002: 46).

Mead thus adds a new dimension of subtlety to the pragmatist critique of the wrong order of progression. What one finds after the emergence is read as antecedent conditions to the emergence, ignoring a) the fact that the novelty had to first happen and only then could one think differently, and b) that reading the post-emerging condition as antecedent to the event reduces the emergent to the scheme, often without being aware of doing so.

How Gendlin is able to work with the challenge of "emergence" owes much to Alfred North Whitehead who in Process and Reality thinks with striking depth and originality into the complex forming of events:

That each entity in the universe of a given concrescence can, so far as its own nature is concerned, be implicated in that concrescence in one or other of many modes; but in fact it is implicated only in one mode: that the particular mode of implication is only rendered fully determinate by that concrescence, though it is conditioned by the correlate universe (Whitehead 1979).

Gendlin draws heavily on Whitehead's notion of "concrescence" in his own conception of the responsively-creative forming of life events. We see this especially in Chapter IV, where with the verb "eveving" ("everything interaffected by everything") Gendlin shows that how something participates in the forming of something else need not have been already a part of it. There is a shifting of the ground here, concerning from "where" one thinks. Where Whitehead describes, and produces a metaphysics, Gendlin uncovers the assumption that there is a place from where one can describe reality. By speaking from the very process of speaking, Gendlin explicates, changes, and furthers the "what it is about," making it live now, taking it on further, and saving what matters most-precisely by letting it change! Gendlin himself admits that his model would not have been possible without Whitehead. 
Of the several continental thinkers who are strong influences upon Gendlin we want to emphasize the impact of Dilthey. His philosophy was the subject matter of Gendlin's master thesis. With Dilthey, Gendlin becomes aware of the limitations of the Kantian concepts. Dilthey's hermeneutics are one more formative inspiration for the overcoming of a wrong order of progression, this time with a special epistemological focus:

Using Dilthey, we can turn Kant around: Living is inherently a kind of understanding not because concepts are at work in it; rather concepts are derived from how living makes sense. And there can be new living and new sense-making. Experiencing is itself a kind of understanding, and we can also hold the converse: Understanding is never just an about; it is itself a kind of experiencing, a new further living. (Gendlin 1994: 386).

Dilthey's "Erleben" ("experiencing") undermines not only the classical concept of experience as a noun, but also the presumed a priori status of categories, considered as existing prior to any kind of cognitions and thus to experience itself. Dilthey critiques any such priority, showing how historically-formed, daily experiencing comes first, and is implicitly required to understand concepts and basic categories themselves. Dilthey also demonstrates how erleben deepens our understanding of categories, as well as how it generates new ones. His triad-experiencing, expression and understanding-bears fruit in Gendlin's thinking move termed "direct reference," which is implicitly used throughout all of Gendlin's work, and is most fully explicated in A Process Model Chapter VIII.

During his formative years in philosophy at the University of Chicago, Gendlin meets Carl Rogers revolutionizing the field of psychotherapy by emphasizing the therapeutic process instead of settled psychological structures. The mutual inspiration between the two men is well known. ${ }^{11}$ Through his involvement in the university's Counseling Center, Gendlin is sensitized to the interactionallyintricate relationship of experiencing and articulation, which leads him beyond the paradigmatic approaches in epistemology and philosophy of language. This opens new kinds of questions for Gendlin, for example about the role of "felt sense" in the precise yet not logical transition from one explication to the next. At the same time, the concrete practice at the Counseling Center gives Gendlin the opportunity to rigorously study the actual process of experiencing and feeling in its relationship with symbolizing. Gendlin's cooperation with Rogers in clinical practice, research and theory, deepens and extends the approaches in which Gendlin has been philosophically trained. Working directly with people in distress, the challenge in therapy is to make real change; Gendlin needs to engage in thinking that facilitates and can be an integral part of the changing that is needed. Put in the terms of classical pragmatism, the standard in thinking should be set by what works and matters in actual experience. In regard to the unforeseeable insights emergent in actual doing, Gendlin writes:

\footnotetext{
11 Spiegelberg writes: “Apparently, Gendlin's share was strongest in the development of Rogers' concept of self as a process of experiencing." (Spiegelberg 1972: 154).
} 
Something about doing eluded the pretended determinism of the different interpretations. Instead, assumptions and values could be seen as generated from practice, and modified by it (Gendlin 1997a).

Quite against the post-modernist conclusion that all systemic thinking is ultimately relative (and that therefore it doesn't really matter what one thinks) Gendlin engages philosophy exactly as mattering, and perhaps even only as mattering.

Gendlin meets these earlier thinkers at their strongest and farthest places of achievement. It's as if they have gone as far as they could with their respective endeavors, and now Gendlin gathers them together and goes still further, answering as best he can the collective need to think better than we currently do. In this light, Gendlin's recommendation that we consider his concepts "as if they came out of nowhere" seems almost like a joke-they truly do not "come out of nowhere"! Instead, we might take the first sentence of Gendlin's main work as an invitation to leave behind old categories, to refrain from boxing thinking into school-distinctions (and the prejudices that go with them), and instead meet concepts and terminologies as if they came from nowhere, in order to find for oneself the differences they make.

Open Access This article is distributed under the terms of the Creative Commons Attribution 4.0 International License (http://creativecommons.org/licenses/by/4.0/), which permits unrestricted use, distribution, and reproduction in any medium, provided you give appropriate credit to the original author(s) and the source, provide a link to the Creative Commons license, and indicate if changes were made.

\section{References}

Adorno, Theodor. 1975. Negative Dialektik. Frankfurt/M.: Suhrkamp.

Barad, Karen. 2007. Meeting the Universe Halfway: Quantum Physics and the Entanglement of Matter and Meaning. Durham and London: Duke University Press.

Cavell, Stanley. 1979. The Claim of Reason: Wittgenstein, Skepticism, Morality, and Tragedy. Oxford: Clarendon Press.

Chalmers, David. 1996. The Conscious Mind: In Search of a Fundamental Theory. New York: Oxford University Press.

Claxton, Guy. 2006. Thinking at the Edge: Developing Soft Creativity. Cambridge journal of education 36 (3): $351-362$.

Deacon, Terrence. 2012. Incomplete Nature: How Mind Emerged from Matter. New York: W. W. Norton and Company.

Deloch, Heinke. 2010. Das Nicht-Sagbare als Quelle der Kreativität: E.T. Gendlins Philosophie des Impliziten und die Methode Thinking at the Edge. In Sprachspiele verstrickt-oder: wie man der Fliege den Ausweg zeigt; Verflechtungen von Wissen und Können, ed. S. Tolksdorf, and H. Tetens, 259-284. Berlin: De Gruyter.

Dewey, John. 1938. Logic: The Theory of Inquiry. New York: Henry Holt and Company.

Dewey, John. 1984. Qualitative Thought. In The Later Work Of John Dewey: 1925-1953, Vol. 5: 1929-1930, ed. Jo Ann Boydston, 243-262. Carbondale, IL: Southern Illinois University Press.

Flanagan, Owen. 2009. The Really Hard Problem: Meaning in a Material World. Cambridge, MA: MITPress.

Gendlin, Eugene. 1962. Experiencing and the Creation of Meaning. Evanston, IL: Northwestern University Press.

Gendlin, Eugene. 1967. An analysis of What is a thing? In What is a thing?, ed. M. Heidegger (trans: Barton W.B. \& Deutsch, V.), 247-296. Chicago: Henry Regnery.

Gendlin, Eugene. 1981. Focusing and the Development of Creativity. The Folio 1 (1): 13-16. 
Gendlin, Eugene. 1986. Heidegger and forty years of silence. In Proceedings of the 20th annual Heidegger conference, ed. M. Frings, 48-56. Chicago: DePaul University.

Gendlin, Eugene. 1989. Phenomenology as non-logical steps. In E.F. Kaelin \& C.O. Schrag (Eds.), Analecta Husserliana: Vol. 26. American phenomenology: Origins and developments, 404-410. Also available at http://www.focusing.org/bios/gendlin_phen_as_nonlogical_steps.html. Accessed 05 Oct 2015.

Gendlin, Eugene. 1994. Response. Human Studies 17: 3.

Gendlin, Eugene. 1997a. Conference-Invitation: After Postmodernism. New York: The Focusing Institute. http://www.focusing.org/gendlin/docs/gol_2233.html. Accessed 05 Oct 2015.

Gendlin, Eugene. 1997b. Reply to Scharff. In Language Beyond Postermodernism: Saying and Thinking in Gendlin's Philosophy, ed. David Levin, 297. Evanston, IL: Northwestern University Press.

Gendlin, Eugene. 2004. Introduction to Thinking at the Edge. The Folio 19: 1-8.

Gendlin, Eugene. 2007. Focusing. New York: Bantam.

Gendlin, Eugene. 2012. Line by Line Commentary on Aristotle's De Anima, Vols. I \& II. Spring Valley, NY: Focusing Institute.

Gendlin, Eugene. 2017a. A Process Model. Evanston, IL: Northwestern University Press.

Gendlin, Eugene. 2017b. What Controls Dialectic? Commentary on Plato's Symposium. In Saying What We Mean: Implicit Precision and the Responsive Order: Essays by Eugene T. Gendlin, ed. Edward S. Casey, and Donata M. Schoeller. Evanston, IL: Northwestern University Press.

Gendlin, Eugene. 2017c. Befindlichkeit: Heidegger and the Philosophy Of Psychology. In Saying What We Mean: Implicit Precision and the Responsive Order: Selected Works by Eugene T. Gendlin, ed. Edward S. Casey, and Donata M. Schoeller. Evanston, IL: Northwestern University Press.

Hegel, Georg. 1970. Phänomenologie des Geistes. Frankfurt: Suhrkamp.

Jung, Matthias. 2009a. Der bewusste Ausdruck. Anthropologie der Artikulation. Berlin/New York: De Gruyter.

Jung, Matthias. 2009b. Handlung, Erleben, Mitteilung - Bewusstsein als Interaktionsphase. In Funktionen des Erlebens. Neue Perspektiven des Bewusstseins, ed. Matthias Jung, and Jan-Christoph Heilinger, 217-253. Berlin/New York: De Gruyter.

Kant, Immanuel. 1998. Prolegomena zu einer jeden künftigen Metaphysik, die als Wissenschaft wird auftreten können. Stuttgart: Reclam.

Mahrer, Alvin. 2006. The Creation of New Ideas in Psychotherapy: A Guidebook. Ross-on-Wye: PCCS Books.

Merleau-Ponty, Maurice. 1945. Phénoménologie de la Perception. Paris: Gallimard.

Mead, George H. 2002. Philosophy of the Present. New York: Prometheus Books.

Noë, Alva. 2009. Out of Our Head: Why You Are Not Your Brain, and Other Lessons from the Biology of Consciousness. New York: Hill and Wang.

Ratcliffe, Matthew. 2008. Feelings of Being: Phenomenology, Psychiatry and the Sense of Reality. New York: Oxford University Press.

Schoeller, Donata. 2016. Somatic-Semantic Shifting: Articulating Embodied Cultures. In Thinking Thinking: Practicing Radical Reflection, ed. Donata Schoeller, and Vera Saller, 112-136. Freiburg: Alber.

Spiegelberg, Herbert. 1972. Phenomenology in Psychology and Psychiatry. A Historical Introduction. Evanston, IL: Northwestern University Press.

Tokumaru, Satoko. 2011. Qualitative research with TAE steps: Thinking at the edge: Theory and applications (trans: Mariyo Kida). Hiroshima: Keisuisha.

Walkerden, Greg. 2005. Felt Knowing: A Foundation for Local Government Practice. In Social Learning in Environmental Management: Towards a Sustainable Future, ed. M. Keen, V.A. Brown, and R. Dyball, 170-187. London: Earthscan.

Walkerden, Greg. 2009. Researching and Developing Practice Traditions Using Reflective Practice Experiments. Quality \& Quantity 43 (2): 249-263.

Whitehead, Alfred North. 1979. Process and Reality. New York: Free Press.

Wittgenstein, Ludwig. 2001. Philosophical Investigations (trans: Anscombe, G.E.M.). Oxford: Blackwell Publishing. 